\title{
The association of GSTTI deletion polymorphism with lung cancer risk among Chinese population: evidence based on a cumulative meta-analysis
}

This article was published in the following Dove Press journal:

OncoTargets and Therapy

12 October 2015

Number of times this article has been viewed

\section{Yadong Wang' \\ Haiyan Yang ${ }^{2}$ \\ Haiyu Wang'}

'Department of Toxicology, Henan Center for Disease Control and Prevention, Zhengzhou, People's Republic of China; ${ }^{2}$ Department of Epidemiology, School of Public Health, Zhengzhou University, Zhengzhou, People's Republic of China
Correspondence: Yadong Wang Department of Toxicology, Henan Center for Disease Control and Prevention, No 105 of South Nongye Road, Zhengzhou 450016, People's Republic of China

Tel +8637168089043

Fax +86 37I 68089043

Email wangyd76@163.com
Objective: Previous studies investigating the relationship between glutathione S-transferase T1 (GSTT1) gene deletion polymorphism and lung cancer risk among Chinese population produced inconsistent results. To obtain a precise conclusion, we performed this meta-analysis to evaluate the association between GSTT1 deletion polymorphism and lung cancer risk among Chinese population.

Methods: The databases of Medline/PubMed, Embase, Web of Science, Wanfang Med Online, and Chinese National Knowledge Infrastructure were searched. The strength of the association was assessed by odds ratio (OR) with $95 \%$ confidence intervals $(95 \% \mathrm{CI})$.

Results: Overall, we found an increased lung cancer risk among subjects carrying GSTT1 null genotype compared with those carrying present genotype ( $\mathrm{OR}=1.31,95 \% \mathrm{CI}: 1.12-1.52)$ on the basis of 20 studies with 3,351 cases and 4,683 controls. We also observed an increased risk of lung cancer among subjects carrying GSTT1 null genotype compared with those carrying present genotype in stratified analyses $(\mathrm{OR}=1.31,95 \% \mathrm{CI}$ : $1.11-1.55$ for healthy subjects-based control; OR $=2.29,95 \%$ CI: $1.84-2.85$ for squamous cell carcinoma and OR $=1.47,95 \% \mathrm{CI}$ : $1.22-1.77$ for adenocarcinoma, respectively).

Conclusion: This meta-analysis suggested that GSTT1 deletion polymorphism might contribute to lung cancer risk among Chinese population.

Keywords: lung cancer, risk, GSTT1, polymorphism, meta-analysis, Chinese

\section{Introduction}

Lung cancer was the most commonly diagnosed cancer as well as the leading cause of cancer death in males globally, and it was the fourth most commonly diagnosed cancer and the second leading cause of cancer death among females in 2008. ${ }^{1}$ In the United States, there were about 228,190 estimated new lung cancer cases and 159,480 estimated deaths in 2013. ${ }^{2}$ In the People's Republic of China, lung cancer increased $465 \%$ during the past 30 years and became the leading cause of cancer death in the current decade. It is estimated that over one million Chinese will be diagnosed with lung cancer by the year $2025 .{ }^{3}$

Lung cancer has been considered as a disease determined solely by environmental exposure, such as exposure to cigarette smoke and asbestos. ${ }^{4,5}$ However, only a small proportion of persons who are exposed to such risk factors will develop lung cancer, which suggests that an individual's susceptibility might contribute to lung cancer risk. Recently, more and more results have supported the hypothesis that common genetic variations of drug-metabolizing enzyme genes may be of importance in determining an individual's sensitivity to develop lung cancer. ${ }^{6}$

Glutathione S-transferase theta-1 (GSTT1), a member of glutathione S-transferases (GSTs), is a kind of phase II detoxification enzyme that is involved in detoxifying 
several kinds of carcinogens such as benzo(a)pyrene present in tobacco smoke. ${ }^{7,8}$ GSTT1 deletion polymorphism is known to abolish enzyme activities and modulate lung cancer risk. ${ }^{9}$ Lan et al, ${ }^{10}$ for the first time, explored the association of GSTT1 deletion polymorphism with lung cancer risk in the Chinese population in 1999. After that, a series of epidemiological studies investigated this association in the Chinese population, ${ }^{11-30}$ successively. However, the conclusions by previous studies remained controversial rather than conclusive. This urged us to perform this meta-analysis using the updated data, which aims at deriving a precise estimate of GSTT1 deletion polymorphism associated with lung cancer risk among Chinese population.

\section{Materials and methods}

\section{Literature source and analytical methods}

Systematic searches were conducted through the databases of Medline/PubMed, Embase, Web of Science, Wanfang Med Online, and Chinese National Knowledge Infrastructure, with the following keywords: "lung cancer" or "lung neoplasm" or "lung carcinoma" and "GSTT1" or "glutathione S-transferase T1" and "polymorphism" and "Chinese" or "China." The starting date for searched publications was January 1, 1990 and the ending date of searched publications was January 31, 2015. We also searched the reference list of relevant publications to identify additional studies manually.

Criteria for inclusion: 1) the subjects of study must be Chinese; 2) papers should include GSTT1 deletion polymorphism and lung cancer risk; 3) case-control study and cohort study; and 4) complete data on genotype of GSTT1 deletion polymorphism for calculating odds ratio (OR) with 95\% confidence intervals (95\% CI). Accordingly, reviews and repeated or overlapping literatures were excluded. If studies contained overlapping cases and/or controls, the latest publication including more information was preferred. We only included journal articles, and not dissertations.

In total, 38 published studies were identified which studied the association between GSTT1 deletion polymorphism and lung cancer risk among Chinese population. We reviewed all papers in accordance with the aforementioned criteria defined and excluded 5 dissertations, 4 reviews, ${ }^{31-34}$ and 9 overlapping articles. ${ }^{10,35-42}$ Therefore, 20 studies were selected for our study.

\section{Data extraction}

Data were extracted and tabulated first, and then inputted into an electronic database. The following information was extracted from each study: authors' names, year of publication, area, source of control, number of cases and controls, genotype frequency, and stratified factors. Characteristics of individual studies are summarized in Table 1.

\section{Quantitative data synthesis}

A meta-analysis was conducted to evaluate the relationship between GSTT1 deletion polymorphism and lung cancer risk among Chinese population. The heterogeneity was assessed

Table I General information of selected studies in this meta-analysis

\begin{tabular}{|c|c|c|c|c|c|}
\hline Study & Area & Source of control & Number of cases & Number of controls & Stratified factors \\
\hline Cao et al'l & Hunan & Healthy subjects & 104 & 205 & Histological type \\
\hline Chan-Yeung et al ${ }^{12}$ & Hong Kong & Healthy subjects & 229 & 197 & \\
\hline Fowke et $\mathrm{al}^{13}$ & Shanghai & Healthy subjects & 208 & 784 & \\
\hline He and $\mathrm{Chan}^{14}$ & Yunnan & Healthy subjects & 61 & 46 & \\
\hline Jiang et $\mathrm{al}^{15}$ & Inner Mongalia & Healthy subjects & 322 & 456 & Smoke \\
\hline Lan et $\mathrm{al}^{16}$ & Yunnan & Healthy subjects & 122 & 122 & \\
\hline Liang et al $^{17}$ & Jiangsu & Hospitalized patients & 152 & 152 & Histological type \\
\hline Liang et $\mathrm{al}^{18}$ & Guangxi & Hospitalized patients & 68 & 70 & \\
\hline Liu et al $^{19}$ & Jilin & Healthy subjects & 100 & 135 & Smoke \\
\hline London et $\mathrm{al}^{20}$ & Shanghai & Healthy subjects & 232 & 710 & \\
\hline Ma et $\mathrm{al}^{21}$ & Sichuan & Healthy subjects & 125 & 125 & Sex \\
\hline Pan et $\mathrm{al}^{22}$ & Jiangxi & Hospitalized patients & 523 & 523 & Smoke, histological type and sex \\
\hline Qi et $\mathrm{al}^{23}$ & Gansu & Hospitalized patients & 53 & 72 & Smoke, histological type and age \\
\hline Wang et $\mathrm{al}^{24}$ & Beijing & Hospitalized patients & 112 & 119 & Smoke \\
\hline Wang et $\mathrm{al}^{25}$ & Henan & Healthy subjects & 77 & 107 & Histological type \\
\hline Wang et $\mathrm{al}^{26}$ & Henan & Healthy subjects & 209 & 256 & \\
\hline Yuan et $\mathrm{al}^{27}$ & Sichuan & Healthy subjects & 150 & 152 & Smoke and histological type \\
\hline Zhang et $\mathrm{al}^{28}$ & Yunnan & Healthy subjects & 110 & 100 & \\
\hline Zhang et $\mathrm{al}^{29}$ & Guangdong & Healthy subjects & $|6|$ & 165 & Smoke, histological type and sex \\
\hline Zhao et $\mathrm{al}^{30}$ & Singapore & Hospitalized patients & 233 & 187 & \\
\hline
\end{tabular}


by Cochrane $Q$ statistics test. ${ }^{43}$ Data were combined using either a fixed-effects model or a random-effects model depending on the results of heterogeneity test. A fixedeffects model is used when there is no heterogeneity, while a random-effects model is used when heterogeneity exists. ${ }^{43}$ Cumulative meta-analysis was performed to investigate the tendency of results by accumulating single study year by year. ${ }^{44}$ Funnel plot was drawn to evaluate the publication bias. Egger's test (an adjusted rank correlation test is proposed as a technique for identifying publication bias) ${ }^{45}$ and Begg's test (a linear regression approach is used to measure funnel plot asymmetry on the natural logarithm scale of the $\mathrm{OR})^{46}$ were applied to assess the symmetry of funnel plot. Sensitivity analysis was performed by deleting one study each time. ${ }^{44}$

All of the statistical analyses were performed using Review Manager (Version 5.0.24, The Cochrane Collaboration) and STATA 10.0 software package (Stata Corporation, College Station, TX, USA). All the tests were two-sided; a $P$-value of 0.05 for any test or model was considered to be statistically significant.

\section{Results}

\section{Meta-analysis databases}

A database was created according to the extracted information from selected articles. Some essential information is listed in Table 1. It indicates the study (first author et al), year of publication, area, source of control, number of cases and controls, and stratified factors. There were a total of 20 studies, with 3,351 cases and 4,683 controls concerning the association of GSTT1 deletion polymorphism with lung cancer risk among Chinese population. The frequency of GSTT1 null genotype was $53.4 \%$ and $48.0 \%$ in cases and controls, respectively.

\section{Test of heterogeneity}

Table 2 shows the association between GSTT1 deletion polymorphism and lung cancer risk among Chinese population. Our results showed that there was no heterogeneity for GSTT1 null genotype versus present genotype in the subgroup analyses of squamous cell carcinoma and adenocarcinoma. Therefore, we calculated the summary ORs for them with a fixed-effects model. Random-effects model was used to calculate the summary ORs for the rest.

\section{Quantitative data synthesis}

Table 2 listed the summary ORs of the association between GSTT1 deletion polymorphism and lung cancer risk among Chinese population on the basis of 3,351 cases and 4,683 controls. Overall, there was a statistically significant correlation of GSTT1 null genotype with an increased lung cancer risk among Chinese population, and the summary OR was 1.31 (95\% CI: 1.12-1.52; Figure 1). The cumulative metaanalysis accumulated the studies according to the year of publications, which may determine whether new studies are needed or not. Our results showed that there was still a significant association between GSTT1 deletion polymorphism and lung cancer risk among Chinese population; the cumulative OR was 1.31 with $95 \%$ CI: 1.12-1.52 (Figure 2).

In subgroup analysis for source of control, we observed an increased risk of lung cancer among subjects carrying GSTT1 null genotype compared with those carrying present genotype in healthy subjects-based controls (OR $=1.31$, 95\% CI: 1.11-1.55), but not in hospitalized patient-based controls (OR $=1.28,95 \%$ CI: $0.89-1.83$ ). We observed an increased risk of lung squamous cell carcinoma and lung adenocarcinoma among subjects carrying GSTT1 null genotype compared with those carrying present genotype in stratified analysis by histological subtype (OR $=2.29$,

Table 2 Combined ORs on the relation of the GSTTI deletion polymorphism to lung cancer risk among Chinese population

\begin{tabular}{|c|c|c|c|c|c|c|c|c|c|c|c|}
\hline \multirow[t]{2}{*}{ Null versus present } & \multirow[t]{2}{*}{$\begin{array}{l}\text { Cases/ } \\
\text { controls }\end{array}$} & \multicolumn{2}{|c|}{$\begin{array}{l}\text { Heterogeneity } \\
\text { test }\end{array}$} & \multirow[t]{2}{*}{$\begin{array}{l}\text { Combined } \\
\text { OR }(95 \% \mathrm{Cl})\end{array}$} & \multicolumn{2}{|c|}{ Hypothesis test } & \multirow[t]{2}{*}{$d f$} & \multicolumn{2}{|c|}{ Begg's test } & \multicolumn{2}{|c|}{ Egger's test } \\
\hline & & Q & $P$-value & & $\mathbf{Z}$ & $P$-value & & $\mathbf{Z}$ & $P$-value & $t$ & $P$-value \\
\hline Total & $3,35 \mathrm{I} / 4,683$ & 46.23 & 0.0005 & $1.31(1.12-1.52)$ & 3.44 & 0.0006 & 19 & 0.23 & 0.820 & 0.56 & 0.586 \\
\hline \multicolumn{12}{|l|}{ Stratified by source of control } \\
\hline Healthy subjects & $2,210 / 3,560$ & 27.75 & 0.01 & $1.31(1.11-1.55)$ & 3.14 & 0.02 & 13 & 1.09 & 0.274 & 1.51 & 0.156 \\
\hline Hospitalized patients & $I, 14 I / I, 123$ & 18.13 & 0.003 & $1.28(0.89-1.83)$ & 1.34 & 0.18 & 5 & 0.38 & 0.707 & 0.44 & 0.683 \\
\hline \multicolumn{12}{|l|}{ Stratified by smoking status } \\
\hline Smokers & $680 / 673$ & 18.09 & 0.003 & $1.54(0.97-2.43)$ & 1.84 & 0.07 & 5 & 0.00 & 1.000 & 0.45 & 0.674 \\
\hline Nonsmokers & $636 / 884$ & 15.45 & 0.02 & $\mathrm{I} .03(0.70-1.5 \mathrm{I})$ & 0.14 & 0.89 & 6 & 0.75 & 0.452 & 1.10 & 0.334 \\
\hline \multicolumn{12}{|c|}{ Stratified by histological subtype } \\
\hline Squamous cell carcinoma & $520 / 1,113$ & 8.66 & 0.12 & $2.29(1.84-2.85)$ & 7.45 & $<0.0000 \mathrm{I}$ & 5 & 2.25 & 0.024 & 2.59 & 0.061 \\
\hline Adenocarcinoma & $691 / 1,350$ & 4.36 & 0.63 & $1.47(1.22-1.77)$ & 4.03 & 0.0001 & 6 & 1.20 & 0.230 & 1.46 & 0.205 \\
\hline
\end{tabular}

Abbreviations: OR, odds ratio; GSTTI, glutathione S-transferase TI; Cl, confidence interval. 


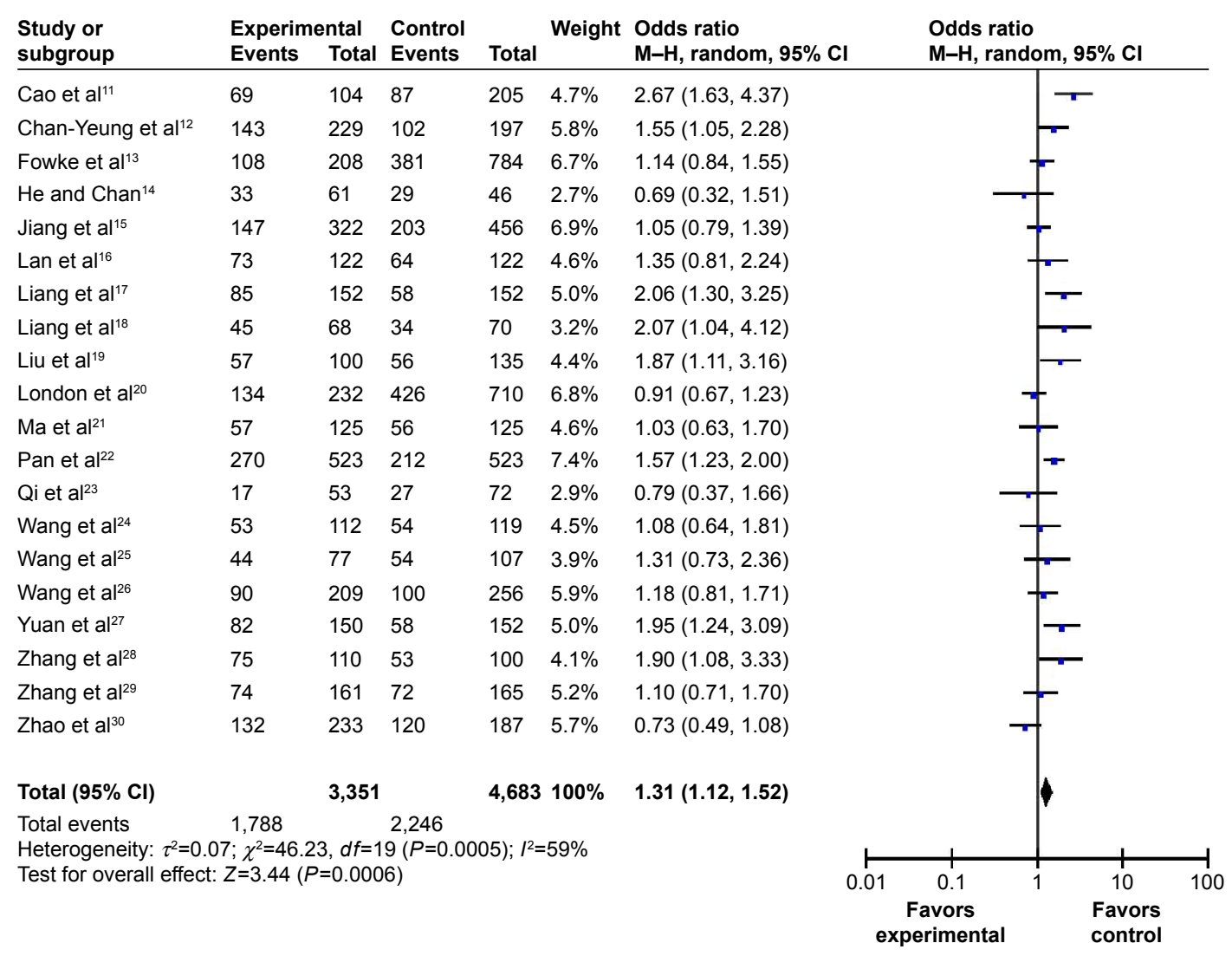

Figure I Forest plot of OR for GSTTI deletion polymorphism associated with lung cancer risk among Chinese population. Abbreviations: GSTTI, glutathione S-transferase TI; OR, odds ratio; Cl, confidence interval; $\mathrm{M}-\mathrm{H}$, Mantel-Haenszel test.

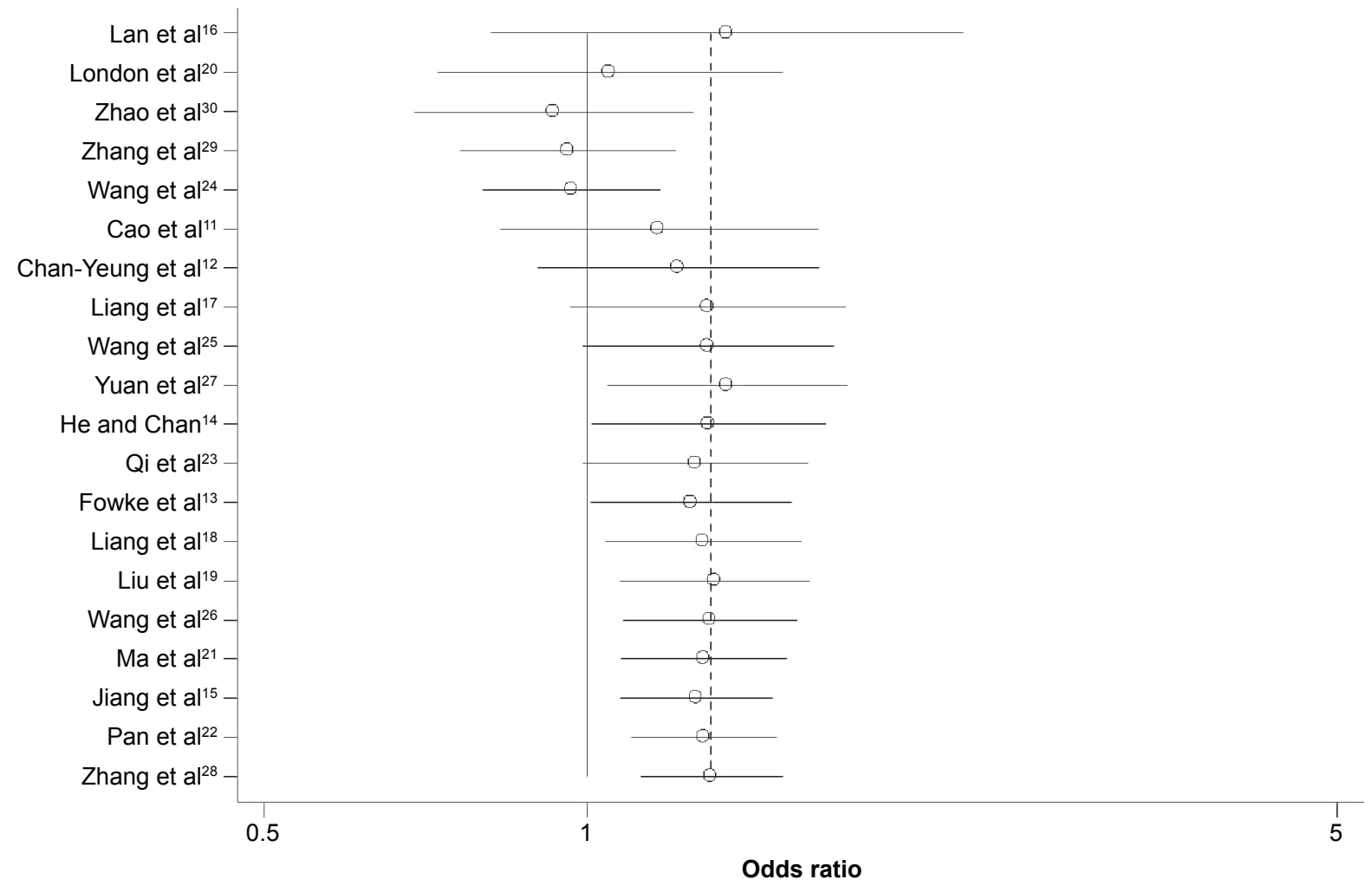

Figure 2 Forest plot for cumulative meta-analysis of OR for GSTTI deletion polymorphism associated with lung cancer risk among Chinese population. Abbreviations: GSTTI, glutathione S-transferase TI; OR, odds ratio. 
95\% CI: $1.84-2.85$ and OR $=1.47,95 \%$ CI: $1.22-1.77$, respectively). We did not observe any association between GSTT1 null genotype and lung cancer risk stratified by smoking status (OR $=1.54,95 \%$ CI: $0.97-2.43$ for smokers and $\mathrm{OR}=1.03,95 \% \mathrm{CI}$ : $0.70-1.51$ for nonsmokers, respectively; Table 2).

\section{Bias diagnosis}

Publication bias was examined by using funnel plot analysis. The shape of the funnel plot seemed to be approximately symmetrical (Figure 3). Both Egger's test and Begg's test suggested that publication bias might have few effects on the summary estimates, except for the subgroup analysis of squamous cell carcinoma, owing to $P$-value being equal to 0.024 in Begg's test.

\section{Sensitivity analysis}

We performed a sensitivity analysis to determine the influence of individual dataset on the summary OR by consecutively deleting individual studies. The combined OR was not significantly altered by deleting each selected study sequentially, which indicated that our results were stable and robust (Figure 4).

\section{Discussion}

GSTT1 gene is mapped on chromosome 22q11.23. It is 8,146 bp in length, consisting of five exons and four introns, which

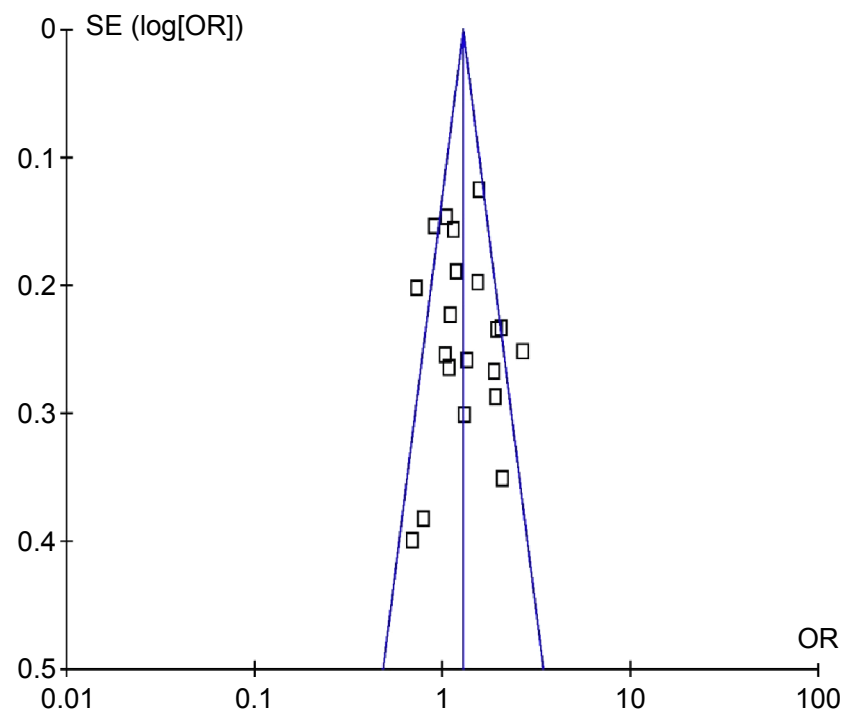

Figure 3 Funnel plot analysis to detect publication bias for GSTTI deletion polymorphism associated with lung cancer risk among Chinese population. Abbreviations: GSTTI, glutathione S-transferase TI; OR, odds ratio; SE, standard error of mean.

encodes a cytoplasmic protein of 240 amino acid residues with a molecular weight of $28-\mathrm{kDa}$. GSTT1 gene has a functional and nonfunctional allele. Homozygosity for the nonfunctional allele of GSTT1 (null genotype) gene causes an absence of GSTT1 enzyme activity. ${ }^{47}$ Individuals who carry homozygous deletions in this gene are thought to be at increased risks for malignancies. ${ }^{8}$ Studies have shown that the

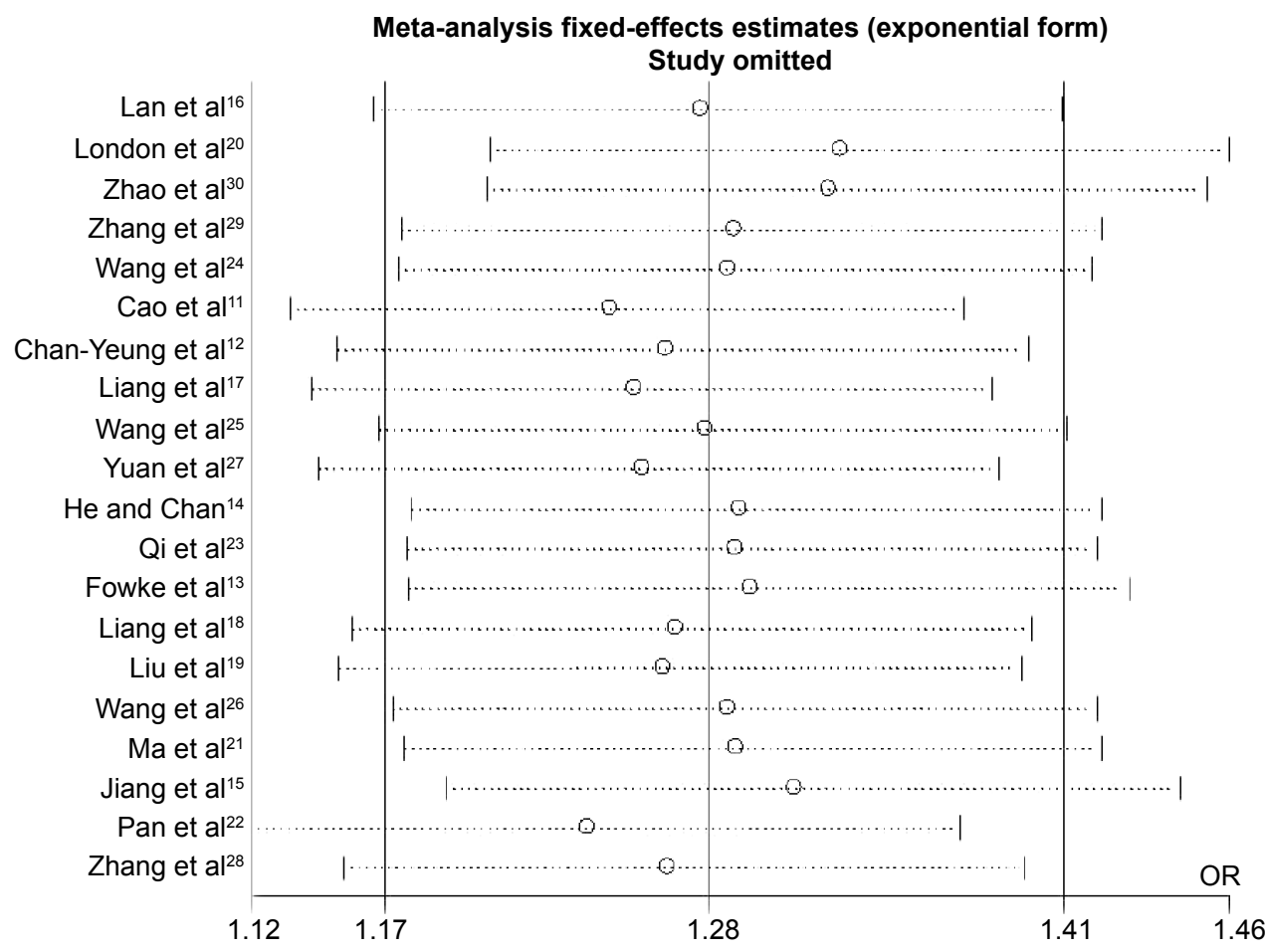

Figure 4 Sensitivity analysis on the association between GSTTI deletion polymorphism and lung cancer risk among Chinese population. Abbreviation: GSTTI, glutathione S-transferase TI. 
GSTT1 gene deletion have effects on survival and clinical outcomes of lung cancer patients. Ruano-Ravina et $\mathrm{al}^{48}$ reported that lung cancer patients with deleted GSTT1 genotype had a significantly shorter survival than those with present GSTT1 genotype. Sreeja et $\mathrm{al}^{49}$ reported that the GSTT1 -/- genotype along with stage was significantly associated with overall survival and was found to be an independent prognostic factor for shorter lung cancer survival. Gonlugur et al's ${ }^{50}$ study showed that none of the patients with GSTT1 null genotype, but $30 \%$ of the patients with GSTT1-positive genotype had liver metastasis among 81 lung cancer patients. ${ }^{50}$

Several meta-analyses explored the association of GSTT1 null genotype with the development of several kinds of cancers among Chinese population. ${ }^{51-57}$ In this paper, we performed a systematic literature review to comprehensively evaluate the association of GSTT1 deletion polymorphism with lung cancer risk among Chinese population. We also evaluated the possible effect modifications by source of control, smoking status, and histological subtype. In summary, we observed an increased lung cancer risk among Chinese population with GSTT1 null genotype compared with those carrying present genotype. To our knowledge, four published papers have addressed the association between GSTT1 deletion polymorphism and lung cancer risk among Chinese population. However, the conclusions are mixed, for example, three previous meta-analyses observed a positive association between GSTT1 null genotype and an increased lung cancer risk among Chinese population, ${ }^{31,33,34}$ but one not. ${ }^{32}$ Furthermore, there are several key limitations in all four previous meta-analyses. Namely, one eligible paper ${ }^{14}$ published before 2010 was not included in Wang et al's paper; ${ }^{34}$ two eligible papers ${ }^{13,25}$ published before 2013 were not included in Liu et al's paper ${ }^{32}$ and Gui et al's paper. ${ }^{31}$ Moreover, the number of cases and controls reported by Gui et $\mathrm{al}^{31}$ for Chan-Yeung et al's study ${ }^{12}$ did not seem in line with the data in Chan-Yeung et al's original publication; ${ }^{12}$ for Liu et al's paper, ${ }^{33}$ two overlapping papers ${ }^{10,37}$ were not excluded and two eligible papers ${ }^{13,40}$ published before 2013 were not included. Therefore, the conclusions from them are not entirely reliable. Our cumulative meta-analysis included 20 selected studies, with 3,351 cases and 4,683 controls on the basis of the updated data. We believed that this current meta-analysis presented a precise estimate of the association between GSTT1 deletion polymorphism and lung cancer risk among Chinese population.

Cigarette smoke is an evident risk factor for lung cancer, and GSTT1 gene is involved in metabolizing various carcinogens present in cigarette smoke. To address the effect of cigarette smoke on the correlation of GSTT1 deletion polymorphism with lung cancer risk, subgroup analysis was conducted in the light of smoking status. We did not observe any association of GSTT1 null genotype with increased risk of lung cancer among smokers or nonsmokers, which might be owing to the relatively small sample size (680 cases in smokers and 636 cases in nonsmokers).

To our knowledge, lung cancer consists of at least three major histological subtypes: squamous cell carcinoma, adenocarcinoma, and small-cell carcinoma. Studies have shown that the development of squamous cell carcinoma and small-cell carcinoma is more often attributed to cigarette smoking, whereas adenocarcinoma is more weakly associated with cigarette smoking than those two subtypes, indicating there is a difference in carcinogenic processes among different histological subtypes of lung cancer. ${ }^{58}$ Therefore, a subgroup analysis was performed according to histological subtype. We observed a statistically significant association of GSTT1 deletion polymorphism with an increased risk of squamous cell carcinoma and adenocarcinoma. We did not perform subgroup analysis in additional histological subtypes, since the sample size for those was relatively small.

There are some potential limitations inherent in this meta-analysis. First, only published articles were included in this study, which may cause publication bias. To address this issue, both Egger's test and Begg's test were applied in this study. Our results demonstrated that the likelihood of key publication bias was negligible in this current meta-analysis. Second, although some confounders were matched perfectly between cases and controls for each study at the beginning of study design, different study might have different eligibility criteria for subjects and different source of controls, which should be considered when expounding the combined effects. When the subgroup analysis was conducted by source of control, the association with GSTT1 null genotype was much stronger in the conducted analysis of studies including healthy subjects as controls ( $\mathrm{OR}=1.31,95 \% \mathrm{CI}: 1.11-1.55)$ than that of studies including hospitalized patients controls $(\mathrm{OR}=1.28$, 95\% CI: 0.89-1.83), indicating that the distribution frequency of GSTT1 null genotype in the hospitalized patients-based control groups might not be representative of the general population. Third, this meta-analysis is based on an unadjusted estimate; thus, a more precise analysis depending on adjusted factors should be conducted in the future study.

In summary, this meta-analysis found that GSTT1 null genotype was associated with an increased risk of lung cancer among Chinese population. Studies with larger sample size 
are required to evaluate gene-gene and gene-environment interactions on GSTT1 deletion polymorphism and lung cancer risk among Chinese population further.

\section{Disclosure}

The authors report no conflicts of interests in this work.

\section{References}

1. Jemal A, Bray F, Center MM, Ferlay J, Ward E, Forman D. Global cancer statistics. CA Cancer J Clin. 2011;61:69-90.

2. Siegel R, Naishadham D, Jemal A. Cancer statistics, 2013. CA Cancer J Clin. 2013;63:11-30.

3. Zhao P, Dai M, Chen W, Li N. Cancer trends in China. Jpn J Clin Oncol. 2010;40:281-285.

4. Nielsen LS, Baelum J, Rasmussen J, et al. Occupational asbestos exposure and lung cancer - a systematic review of the literature. Arch Environ Occup Health. 2014;69:191-206.

5. Luqman M, Javed MM, Daud S, Raheem N, Ahmad J, Khan AU. Risk factors for lung cancer in the Pakistani population. Asian Pac J Cancer Prev. 2014;15:3035-3039.

6. Wang YD, Yang HY, Liu J, Wang HY. Updated meta-analysis of the association between CYP2E1 RsaI/PstI polymorphisms and lung cancer risk in Chinese population. Asian Pac J Cancer Prev. 2014;15: 5411-5416.

7. Marinkovic N, Pasalic D, Potocki S. Polymorphisms of genes involved in polycyclic aromatic hydrocarbons' biotransformation and atherosclerosis. Biochem Med (Zagreb). 2013;23:255-265.

8. Landi S. Mammalian class theta GST and differential susceptibility to carcinogens: a review. Mutat Res. 2000;463:247-283.

9. Phukan RK, Saikia BJ, Borah PK, Zomawia E, Sekhon GS, Mahanta J. Role of household exposure, dietary habits and glutathione S-transferases M1, T1 polymorphisms in susceptibility to lung cancer among women in Mizoram India. Asian Pac J Cancer Prev. 2014;15: 3253-3260.

10. Lan Q, He X, Debra C, Tian W, Lu X, Judy M. Glutathione S transferase GSTM 1 and GSTT 1 genotypes and susceptibility to lung cancer. J Hygiene Res. 1999;28:9-11.

11. Cao YF, Chen HC, Liu XF, et al. Study on the relationship between the genetic polymorphisms of GSTM 1 and GSTT 1 genes and lung cancer susceptibility in the population of Hunan province of China. Life Sci Res. 2004;8:126-132.

12. Chan-Yeung M, Tan-Un KC, Ip MS, et al. Lung cancer susceptibility and polymorphisms of glutathione-S-transferase genes in Hong Kong. Lung Cancer. 2004;45:155-160.

13. Fowke JH, Gao YT, Chow WH, et al. Urinary isothiocyanate levels and lung cancer risk among non-smoking women: a prospective investigation. Lung Cancer. 2011;73:18-24.

14. He DX, Chan Y. The relationship of GSTT1 polymorphism and chromosome 15 aberration in lung cancer patients. Cancer Res Prev Treat. 2006;33:308-310.

15. Jiang XY, Chang FH, Bai TY, Lv XL, Wang MJ. Susceptibility of lung cancer with polymorphisms of CYP1A1, GSTM1, GSTM3, GSTT1 and GSTP1 genotypes in the population of inner Mongolia region. Asian Pac J Cancer Prev. 2014;15:5207-5214.

16. Lan Q, He X, Costa DJ, et al. Indoor coal combustion emissions, GSTM1 and GSTT1 genotypes, and lung cancer risk: a case-control study in Xuan Wei, China. Cancer Epidemiol Biomarkers Prev. 2000; 9:605-608

17. Liang GY, Pu YP, Yin LH. Studies of the genes related to lung cancer susceptibility in Nanjing Han Population, China. Hereditas (Beijing). 2004;26:584-588.

18. Liang KC, Gan LG, Ruan L, Wei ZX, Ma Z. Correlational research of the relationship between genetic polymorphism of GSTM1 and GSTT1 in the Zhuang population and lung cancer. Acta Med Sinica. 2012;25: 813-817.
19. Liu JN, Zhou CC, Piao HM, An CS. Relationship between GSTT1 genetic polymorphism, smoking and lung cancer susceptibility. Basic Clin Med. 2012;32:1194-1197.

20. London SJ, Yuan JM, Chung FL, et al. Isothiocyanates, glutathione S-transferase M1 and T1 polymorphisms, and lung-cancer risk: a prospective study of men in Shanghai, China. Lancet. 2000;356: 724-729.

21. Ma DY, Du GB, Tan BX, Liu M, Zhao YL, Yang MH. Study on genetic polymorphism of GSTM1 and GSTT1 related with susceptibility to lung cancer in the population of Northern Sichuan of China. J Cancer Control Treat. 2013;26:136-139.

22. Pan C, Zhu G, Yan Z, Zhou Y, Liu Z. Glutathione S-transferase T1 and M1 polymorphisms are associated with lung cancer risk in a genderspecific manner. Oncol Res Treat. 2014;37:164-169.

23. Qi XS, Lv HM, Xia Y, et al. A primary case-control study on the relationship between genetic polymorphisms of GSTT1 and lung cancer susceptibility to the people living in high radon-exposed area. Chin Occup Med. 2008;35:361-367.

24. Wang J, Deng Y, Cheng J, Ding J, Tokudome S. GST genetic polymorphisms and lung adenocarcinoma susceptibility in a Chinese population. Cancer Lett. 2003;201:185-193.

25. Wang N, Wu Y, Wu Y, Zhuang D. Research on relationship between deletion of GSTM1, GSTTI genes and susceptibility to lung cancer. J Hygiene Res. 2004;33:586-588.

26. Wang N, Wu Y, Zhou X. Association between genetic polymorphism of metabolizing enzymes and DNA repairing enzymes and the susceptibility of lung cancer in Henan population. J Hygiene Res. 2012;41: 251-256.

27. Yuan TZ, Zhou QH, Zhu W, et al. Relationship between genetic polymorphism of GSTTI gene and inherent susceptibility to lung cancer in Han population in Sichuan, China. Chin J Lung Cancer. 2005;8: $107-111$.

28. Zhang HY, Wu XW, Xaio Y, et al. Genetic polymorphisms of glutathione S-transferase M1 and T1 and evaluation of oxidative stress in patients with non-small cell lung cancer. J China Med Univ. 2014;43: 432-436.

29. Zhang JK, Hu YL, Hu CF, Wang SY. Relationship between genetic polymorphisms of GSTM1 as well as GSTT1 and lung cancer. Chin J Pathophysiol. 2002;18:352-355.

30. Zhao B, Seow A, Lee EJ, et al. Dietary isothiocyanates, glutathione S-transferase -M1, -T1 polymorphisms and lung cancer risk among Chinese women in Singapore. Cancer Epidemiol Biomarkers Prev. 2001; 10:1063-1067.

31. Gui Q, Xiong J, Zhu C, Lu X. The present/null polymorphism in the GSTT1 gene and the risk of lung cancer in Chinese population. Tumour Biol. 2013;34:3465-3469.

32. Liu HZ, Peng J, Zheng F, Wang CH, Han MJ. Lack of assocation of glutathione S-transferase T1 gene null and susceptibility to lung cancer in china: a meta-analysis. Asian Pac J Cancer Prev. 2013;14: 7215-7219.

33. Liu K, Lin X, Zhou Q, et al. The associations between two vital GSTs genetic polymorphisms and lung cancer risk in the Chinese population: evidence from 71 studies. PLoS One. 2014;9:e102372.

34. Wang Y, Yang H, Li L, Wang H. Glutathione S-transferase T1 gene deletion polymorphism and lung cancer risk in Chinese population: a meta-analysis. Cancer Epidemiol. 2010;34:593-597.

35. Zhang JK, Hu YL, Hu CF, Wang SY. Study on genetic polymorphisms of GSTM1 and GSTT1 related with inherent susceptibility to lung cancer in women. Chin J Public Health. 2002;18:273-275.

36. Bai TY, Chang FH, Wang MJ, Wang G, Zhang S. Relationship between GSTT1 and CYP1A1 genetic polymorphisms and lung cancer susceptibility. Chin J Public Health. 2011;27:723-725.

37. Chen HC, Cao YF, Hu WX, et al. Genetic polymorphisms of phase II metabolic enzymes and lung cancer susceptibility in a population of Central South China. Dis Markers. 2006;22:141-152.

38. Fan J, Gan LG, Liang KC, Liang XM. Relationship of GSTM1 and GSTT1 genetic polymorphisms with lung cancer susceptibility in Guangxi Zhuang population. J Oncol. 2010;16:922-925. 
39. Liang GY, Pu YP, Yin LH. Gene interaction of gene polymorphism on lung cancer risk. Chin J Public Health. 2007;23:902-903.

40. Ma DY, Du GB, Tan BX, Liu M, Yang MH. Genetic polymorphism of GSTT1 to lung cancer patients in north Sichuan. Chin J Cancer Prev Treat. 2011;18:989-991.

41. Wang N, Zhou F, Wu YJ, Zhou XL, Wu YM. The relationship between genetic polymorphism of four metabolizing enzymes and susceptibility to lung cancer. Modern Prev Med. 2012;39:4545-4547.

42. Yao W, Wang N, Wu Y, Wu Y. Relationship between deletion of GSTM1, GSTTI genes and susceptibility to lung cancer. Chin J Public Health. 2006;22:1070-1072.

43. DerSimonian R, Laird N. Meta-analysis in clinical trials. Control Clin Trials. 1986;7:177-188.

44. Wang Y, Yang H, Gao H, Wang H. The association between LEPR Q223R polymorphisms and breast cancer risk. Breast Cancer Res Treat. 2015;151:1-6.

45. Egger M, Davey Smith G, Schneider M, Minder C. Bias in meta-analysis detected by a simple, graphical test. BMJ. 1997;315:629-634.

46. Begg CB, Mazumdar M. Operating characteristics of a rank correlation test for publication bias. Biometrics. 1994;50:1088-1101.

47. Pemble S, Schroeder KR, Spencer SR, et al. Human glutathione S-transferase theta (GSTT1): cDNA cloning and the characterization of a genetic polymorphism. Biochem J. 1994;300(Pt 1):271-276.

48. Ruano-Ravina A, Garcia-Basteiro AL, Perez-Rios M, GomezMosquera A, Cerdeira-Carames S, Barros-Dios JM. Lung cancer survival and deletion of GSTM1 and GSTT1 genes. A case-series from Spain. Tumori. 2013;99:445-451.

49. Sreeja L, Syamala V, Hariharan S, et al. Glutathione S-transferase M1, $\mathrm{T} 1$ and $\mathrm{P} 1$ polymorphisms: susceptibility and outcome in lung cancer patients. J Exp Ther Oncol. 2008;7:73-85.
50. Gonlugur U, Pinarbasi H, Gonlugur TE, Silig Y. The association between polymorphisms in glutathione S-transferase (GSTM1 and GSTT1) and lung cancer outcome. Cancer Invest. 2006;24:497-501.

51. Peng J, Liu HZ, Zhu YJ. Null glutathione S-transferase T1 and M1 genotypes and oral cancer susceptibility in China and India - a metaanalysis. Asian Pac J Cancer Prev. 2014;15:287-290.

52. Jin B, Dong P, Li K, Shen B, Xie J. Meta-analysis of the association between GSTT1 null genotype and risk of nasopharyngeal carcinoma in Chinese. Tumour Biol. 2014;35:345-349.

53. Zhao Y, Luo Y, Huang B, et al. GSTT1 null genotype contributes to increased risk of gastric cancer in Chinese population: evidence from a meta-analysis. Tumour Biol. 2013;34:1691-1697.

54. Liu K, Zhang L, Lin X, et al. Association of GST genetic polymorphisms with the susceptibility to hepatocellular carcinoma (HCC) in Chinese population evaluated by an updated systematic meta-analysis. PLoS One. 2013;8:e57043.

55. Chen J, Ma L, Peng NF, Wang SJ, Li LQ. Relationship between GSTT1 gene polymorphism and hepatocellular carcinoma in patients from China. Asian Pac J Cancer Prev. 2012;13:4417-4421.

56. Weng Y, Fei B, He P, Cai M. Glutathione-S-transferase T1 polymorphism is associated with esophageal cancer risk in Chinese Han population. Asian Pac J Cancer Prev. 2012;13:4403-4407.

57. Wang D, Zhang LM, Zhai JX, Liu DW. GSTM1 and GSTT1 polymorphisms and colorectal cancer risk in Chinese population: a metaanalysis. Int J Colorectal Dis. 2012;27:901-909.

58. Sunaga N, Kohno T, Yanagitani N, et al. Contribution of the NQO1 and GSTT1 polymorphisms to lung adenocarcinoma susceptibility. Cancer Epidemiol Biomarkers Prev. 2002;11:730-738.
OncoTargets and Therapy

\section{Publish your work in this journal}

OncoTargets and Therapy is an international, peer-reviewed, open access journal focusing on the pathological basis of all cancers, potential targets for therapy and treatment protocols employed to improve the management of cancer patients. The journal also focuses on the impact of management programs and new therapeutic agents and protocols on

\section{Dovepress}

patient perspectives such as quality of life, adherence and satisfaction The manuscript management system is completely online and includes a very quick and fair peer-review system, which is all easy to use. Visit http://www.dovepress.com/testimonials.php to read real quotes from published authors. 